\title{
Diet components in the management of diabetes
}

\author{
B Y ROBERT W. WELCH \\ Human Nutrition Research Group, Department of Biological and Biomedical Sciences, University \\ of Ulster at Jordanstown, Newtownabbey, Co. Antrim BT37 OQB, Northern Ireland
}

The aims of dietary management in diabetes are manifold. In the long term it is desirable to alleviate any accompanying obesity, minimize vascular and other abnormalities and, if possible, to bring about improvements in plasma glucose control. In the short term it is essential to regulate plasma glucose excursions. Plasma glucose levels show the widest variations in the period immediately following the ingestion of a meal. These variations, which may be accompanied by substantial changes in the levels of circulating hormones, are significantly influenced by the nature of the diet. Diet plays a central role in the management of diabetes and the latest recommendations are outlined. This is followed by a brief description of carbohydrate digestion and a review of the ways in which individual foods and food components may influence post-prandial plasma glucose responses and other factors of importance in diabetic management. Substantial experimental data are available on the relationship between diet and post-prandial glucose. Animal and in vitro studies can assess the potential effects of specific diet constituents and evaluate possible mechanisms of action. However, unless otherwise stated, the data in the present review are derived from human studies.

\section{DIETARY RECOMMENDATIONS FOR DIABETES MELLITUS}

The recent dietary reference values from the UK Department of Health (1991) and the latest recommendations for diabetic diets from the British Diabetic Association (1991) are summarized in Table 1. This shows that the recommended diets for diabetes mellitus and for the general population have evolved to positions where they are broadly similar to each other. Both advocate moderate intakes of fat and protein, low sugar consumption and high intakes of carbohydrate and dietary fibre. The recommended moderate fat intakes are combined with relatively high polyunsaturated fatty acids (PUFA):saturated fatty acids ratios. This is aimed at reducing the risk of atherosclerotic cardiovascular disease which is particularly prevalent in diabetes. Further modifications in dietary fat to increase the intakes of $n-3$ PUFA of marine origin (eicosapentaenoic 20:5n-3, docosahexaenoic 22:6n-3) can improve plasma lipoprotein profiles and induce other changes that may reduce the risk of cardiovascular disease (Phillipson et al. 1985). However, $n-3$ PUFA supplementation has been found to elevate both fasting and post-prandial glucose levels in diabetes (Glauber et al. 1988; Friday et al. 1989) and this intervention cannot be generally advised for diabetic patients.

Diets low in protein may reduce the susceptibility to diabetic nephropathy. However, the overall effects of long-term dietary protein restriction are not fully understood and people with diabetes are currently recommended to maintain a normal protein intake (Horwitz, 1990). Only a modest intake of sugars (sucrose, or fructose if preferred) is recommended in diabetic diets. Non-nutritive sweeteners, specially formulated low-fat foods and low-energy fat substitutes may have a role in the diets of some individuals; however, their use in diabetic diets is not generally recommended (British Diabetic Association, 1991). 
Table 1. Dietary reference values (\% total energy) for the general population and dietary recommendations for people with diabetes mellitus

\begin{tabular}{|c|c|c|}
\hline & $\begin{array}{c}\text { General } \\
\text { population* }\end{array}$ & $\begin{array}{l}\text { Diabctes } \\
\text { mellitus }{ }^{\dagger}\end{array}$ \\
\hline Total fat: & $33-35$ & $30-35$ \\
\hline Saturated fatty acids & $10-11$ & $<10$ \\
\hline Mono-unsaturated fatty acids & $12-13$ & $10-15$ \\
\hline Polyunsaturated fatty acids & $6-10$ & $<10$ \\
\hline Protein + & $9-15$ & $10-15$ \\
\hline Carbohydrate: & $47-50$ & $50-55$ \\
\hline Sugars\$ & $<60 \mathrm{~g} / \mathrm{d}$ & $<25 \mathrm{~g} / \mathrm{d}$ \\
\hline Dietary fibre & $12-24 \mathrm{~g} / \mathrm{d}$ & $>30 \mathrm{~g} / \mathrm{d}$ \\
\hline Salt & $4 \cdot 1 \mathrm{~g} / \mathrm{d}$ & $\begin{array}{c}<6 \mathrm{~g} / \mathrm{d} \\
(<3 \mathrm{~g} / \mathrm{d} \text { if hypertensive })\end{array}$ \\
\hline
\end{tabular}

* Data from Department of Health (1991).

$\div$ Data from British Diabetic Association (1991).

$\$$ For the general population, the lower level is based on adult Reference Nutrient Intake values for protein and adult Estimated Average Requirements for energy; the higher level is based on adult average intakes.

$\S$ Extrinsic sugars for general population; added sucrose or fructose for diabctes.

The high intake of total digestible carbohydrate should be combined with a high intake of dietary fibre. Starch is the major complex digestible carbohydrate in foods, while dietary fibre is derived mainly from plant cell walls. The apparently large differences in fibre intakes for the two diets in Table 1 appear to reflect differences in analytical methods. The dietary fibre values from the Department of Health's (1991) dietary reference values refer to total non-starch polysaccharides (NSP) which comprise the major component of dietary fibre. However, estimates of daily dietary fibre intakes based on NSP values are 6-8 g lower than those based on less-rigorous methods of dietary fibre analysis and which include other components such as lignin (Bingham et al. 1990).

The products of starch digestion will be the major source of post-prandial glucose in diabetic diets which follow current recommendations. However, as outlined later, the rate of starch digestion and absorption varies widely between foods and is affected by a variety of factors including its provenance, processing conditions and the presence of dietary fibre and other constitutents.

\section{STARCH DIGESTION}

Starch is a polymer of glucose which exists in two distinct structural forms, amylose and amylopectin. Amylose is a straight-chain molecule in which the glucose residues are joined entirely by $\alpha-1,4$ linkages. Amylopectin has a predominance of straight-chain $\alpha-1,4$ linkages, but also contains a proportion of $\alpha-1,6$ linkages which confer on it a branched structure. Starch digestion is initiated by salivary $\alpha$-amylase (EC 3.2.1.1) which cleaves alternate $\alpha-1,4$ linkages in both amylose and amylopectin to yield maltose and other products. The activity of this salivary enzyme is inhibited in the stomach by the acid 
secretions of the gastric juice. However, the breakdown of $\alpha-1,4$ linkages is resumed in the small intestine, catalysed by pancreatic $\alpha$-amylase. The products of $\alpha$-amylase digestion comprise a range of glucose oligosaccharides. These include maltose and maltotriose derived from straight-chain domains, and $\alpha$-limit dextrins which contain the $\alpha-1,6$ linkages originating in amylopectin. These digestion products are further degraded to glucose by the glucosidic enzymes of the brush border of the small intestinal epithelium. Glucose, which is the only final digestion product, is absorbed via an active transport system. There are numerous ways in which foods can interact with this digestive process and, thus, influence the rate at which glucose, derived from starch, can reach the circulation.

\section{THE GLYCAEMIC RESPONSE}

Plasma glucose levels rise in response to the ingestion of digestible carbohydrates and return to fasting levels after $2-3 \mathrm{~h}$. This glycaemic response, which can be quantified by monitoring post-prandial plasma glucose, shows wide variations between different foodstuffs even when they are consumed at equivalent levels of digestible carbohydrate (e.g. Crapo et al. 1981). Jenkins et al. (1981) have highlighted these variations and developed the concept of the glycaemic index. The glycaemic index is the integrated post-prandial plasma glucose response to a standard oral load of digestible carbohydrate (usually $50 \mathrm{~g}$ ) in the food under test, in comparison with the response to a reference food, which is usually glucose or white bread. There is a wide range in the glycaemic index of individual foods (Table 2 ). Higher values are generally found in more highly processed foods (Brand et al. 1985), while grain legumes characteristically give the lowest values. These differences have been related to variations in food physical factors and to a range of diet components.

\section{EFFECTS OF DIETARY FIBRE AND THE PHYSICAL CHARACTERISTICS OF FOOD ON INTAKE AND STARCH DIGESTION}

Plant cell wall material, which is the major source of dietary fibre, is composed chiefly of NSP, cellulose, hemicelluloses and pectins. A number of plant exudates and seed gums are also composed of NSP and contribute to total dietary fibre. Cellulose is insoluble in water. However, the gums and a proportion of the pectins and hemicelluloses comprise water-soluble fibre and can yield viscous solutions. Thus, dietary fibre is a complex, heterogenous material whose composition will vary depending on source and whose components may differ in their effects on the digestive tract. Since fibre is the major contributor to cell wall structure, it follows that unrefined foods such as unmilled or wholemeal cereal grains, legume seeds and fruits and vegetables will be good sources of dietary fibre. There are a number of mechanisms whereby dietary fibre or unrefined fibre-rich foods may yield physiological effects of potential benefit in the management of diabetes. These include moderations in post-prandial blood glucose responses and reductions in food intake. However, in unrefined foods it is difficult to distinguish between factors associated with the cellular integrity of the food and the dietary fibre components per se.

In the first stage of digestion, food is mixed with saliva and masticated to produce a moist bolus for deglutition. Disruption of fibrous cell wall structure or fibre depletion can reduce the time taken to eat and also decrease post-prandial satiety (McCance et al. 
Table 2. Glycaemic index values for a range of foods

( $50 \mathrm{~g}$ dietary carbohydrate; relative area under $2 \mathrm{~h}$ blood glucose response curve; data from Jenkins et al. 1981)

\begin{tabular}{lc} 
Food & $\begin{array}{c}\text { Giycaemic } \\
\text { index }\end{array}$ \\
\hline Glucose & 100 \\
Cornflakes & 80 \\
White rice & 72 \\
Potatoes & 70 \\
White bread & 69 \\
All bran & 51 \\
White spaghetti & 50 \\
Oatmeal & 49 \\
Peas & 47 \\
Wholemeal spaghetti & 42 \\
Baked beans (canned) & 40 \\
Lentils & 29 \\
Soya beans & 15 \\
\hline
\end{tabular}

1953; Haber et al. 1977). Thus, the presence of fibrous cell walls in unprocessed foods may decrease intake. This will, in itself, reduce post-prandial glycaemia and may, in the longer term, help to alleviate obesity. Dietary fibre has the potential to reduce intake by a number of mechanisms. However, data from clinical trials on the role of fibre in long-term weight control are inconclusive (Federation of American Societies for Experimental Biology, 1987).

In the stomach, the inhibition of salivary $\alpha$-amylase by gastric acid may be delayed in a fibre-rich starchy food bolus particularly if its consistency is increased by the presence of viscous soluble fibre components. Furthermore, there is evidence that both unrefined fibre-rich cereal grains and isolated fibre components can depress gastric acidification (Vahouny \& Cassidy, 1985). While this may increase the potential for salivary amylase activity in fibre-rich foods, amylolytic activity may be limited by the presence of intact cell walls or by the inhibition of amylase by fibre components (Schneeman \& Gallaher, 1986).

Soluble fibre components can increase the viscosity of the gastric contents. This may reduce the rate of delivery of digesta to the small intestine (Leeds, 1982; Vahouny \& Cassidy, 1985). However, the effects of soluble fibre on gastric emptying are not clear cut and may depend on the nature of the accompanying meal (Low, 1990; Morgan et al. 1990). The effects of insoluble fibres, such as wheat bran or cellulose, on gastric emptying are also equivocal (Vahouny \& Cassidy, 1985; Low, 1990) and may be confounded by variations in particle size since larger food particles, which may be present in unrefined fibre-rich foods, can delay emptying (Meyer et al. 1981). The existence of an interaction between fibre content and particle size is consistent with the reduced glycaemic responses found when whole cereal grains are compared with physically degraded grains (Heaton et al. 1988; Jenkins et al. 1988). Comparisons of starchy meals have shown that the rates of gastric emptying are directly related to glycaemic responses (Torsdottir et al. 1984; Mourot et al. 1988). Thus, changes in gastric emptying rate induced by dietary fibre constitutents or by the physical characteristics of the diet have the potential to influence the glycaemic response. 
After passing into the small intestine the digesta encounters the bile and pancreatic secretions. The insoluble fibre in intact cell walls may limit the access of pancreatic amylase to starch. Components of dietary fibre can also inhibit pancreatic amylase (Schneeman \& Gallaher, 1986). However, this enzyme is secreted in considerable excess and animal studies indicate that soluble fibre components may influence post-prandial glycaemia by increasing the intra-lumen viscosity within the small intestine (Blackburn \& Johnson, 1981). This increase may hinder mixing of enzyme and substrate and also reduce the rate of diffusion of digesta to the brush-border epithelium for the final stage of enzymolysis and absorption. Higher levels of mucin production in the small intestine have been observed in rats fed on soluble and insoluble fibre and this may also contribute to the effects of fibre on nutrient absorption (Schneeman, 1982; Satchithanandam et al. 1990).

Thus, there are a number of interacting mechanisms whereby dietary fibre constituents or fibre-rich foods may modulate glycaemic responses. Wolever (1990) studied the relationship between the glycaemic index and the fibre contents of twenty-five foods and found a significant negative correlation between glycaemic index and total dietary fibre. However, the relationship was weak, with a predictability of only $21 \%$. Correlations involving individual fibre components or combinations of components indicated that they could not explain more than $50 \%$ of the variation in glycaemic index. Furthermore, the insoluble fibre components were generally more highly correlated with glycaemic index than the soluble components (Wolever, 1990). Thus, the contribution of insoluble fibre to the physical integrity of the food may be a more important determinant of glycaemic index than the presence of soluble fibre constituents. In addition other factors associated with fibre-rich foods and which are outlined later may exert significant effects on post-prandial glucose responses.

\section{INFLUENCE OF STARCH CHARACTERISTICS ON STARCH DIGESTION}

Starch source and processing conditions can play important roles in both the rate and completeness of its digestion. As described previously the cell walls in unprocessed foods can limit enzyme access. In contrast, heat processing can gelatinize starch and result in increases in glycaemic response (Collings $e$ t al. 1981). Variations in starch digestibility have led to the development of the concept of resistant starch by Englyst \& MacFarlane (1986) who have classified starch nutritionally into readily digestible starch or into various types of resistant starch. These range from a slowly and partially digested type, such as the raw starch in potato or retrograded starch derived mainly from amylopectin, to a completely indigestible type derived from retrograded amylose and found in some highly processed foods. Thus, the physical nature of starch may affect both the rate and completeness of its digestion.

Starches also vary in the amylose:amylopectin ratio and it has been shown that starches with a high amylose content give lower post-prandial glucose excursions than those high in amylopectin (Goddard et al. 1984; Behall et al. 1989). This difference could be due to a higher level of resistant starch in the high-amylose starch, or to a reduced rate of amylose digestion resulting from differences in granule structure or the presence of starch-lipid complexes in the amylose molecule. Recent results indicate that concomitant differences in viscosity and rates of gastric emptying do not account for the variations in glycaemic response found with starches of varying amylose content (Bornet et al. 1990). 
Starch-protein interactions may also influence the glycaemic response. Gluten-free bread gave a higher glycaemic response than white bread. However, adding gluten to gluten-free bread did not restore the lower glycaemic response (Jenkins et al. 1987). This suggests that there may be intimate associations between starch and gluten which reduce starch digestion.

Seed legumes are high in protein and have starch with a relatively high amylose content. Both these factors may contribute to the generally low glycaemic responses found with seed legumes (Table 1). However, a more important factor may be the physical confinement of the starch granules within cell walls. Cell wall structure is increasingly disrupted with severity of heat processing in legumes (Würsch et al. 1986) which results in concomitant increases in glycaemic response (Traianedes \& O'Dea, 1986).

\section{EFFECT OF OTHER DIETARY COMPONENTS ON STARCH DIGESTION}

The recommended restrictions of salt intake are aimed at reducing the risk of hypertension. Nevertheless, dietary salt has the potential to increase post-prandial glucose responses to starchy meals. This could occur via stimulation of salivary or pancreatic amylase activity or by facilitation of glucose absorption in the small intestine. However, studies on the effects of dictary salt on the glycaemic response have given contradictory results (Thorburn et al. 1986; Gans et al. 1987).

The rate of starch digestion may also be influenced by a wide range of minor compounds which are found in plant foods and which are generally regarded as anti-nutrients. Among these is phytic acid which occurs widely in seeds, where it acts as a phosphorus reserve. The anti-nutrient function of phytic acid is associated with its ability to complex cations and reduce mineral availability. However, significant negative correlations have been found between the glycaemic index of grain foods and their phytic acid contents (Thompson, 1986) This indicates that phytic acid may be a factor in the low glycaemic responses observed with some of these foods and a number of potential mechanisms have been proposed for this effect. These include, chelation of calcium, which is essential for amylase activity, binding of the digestive enzymes or binding directly to starch (Thompson, 1986). Other anti-nutrients found in plant foods and which may also play a role in reducing the rate of starch digestion and absorption include protein inhibitors of amylase (Buonocore \& Silano, 1986) and tannins (Griffiths, 1979), lectins (Jaffé, 1980) and saponins (Birk \& Peri, 1980) which may also reduce the activity of digestive enzymes. If present at a high enough level, lectins and saponins can induce acute toxicity by damaging the small intestinal epithelial cells. However, at very low dietary levels this damage may result in a reduced capacity for mucosal enzymolysis and nutrient absorption without overt toxicity. Although these minor components which are particularly prevalent in seed legumes have the potential to influence glycaemic responses by reducing digestion and absorption, their effects may be reduced by processing or by interactions between them (Fish \& Thompson, 1991) and their practical significance is unclear.

Other compounds which can inhibit the enzymes of carbohydrate digestion in the lumen or at the brush border have been isolated or synthesized. These pharmacological agents which include Acarbose (BAY g 5421) and Miglitol (BAY m 1099) can bc effective in regulating post-prandial glycaemia when administered orally in conjunction 
with dietary constraints. However, dose level is crucial, with excess resulting in carbohydrate malabsorption and associated gastrointestinal disorders (Taylor, 1990).

\section{PRACTICAL SIGNIFICANCE OF VARIATIONS IN GLYCAEMIC RESPONSE}

There are wide variations in the glycaemic responses of individual carbohydrate foodstuffs. These variations have been linked to a large number of physical and chemical factors within the food which may interact with the digestive tract in a variety of ways to yield the net observed effects. Data from individual foodstuffs or food constituents may provide information on potential mechanisms of action. However, in practice mixed meals are eaten which may include digestible carbohydrate from a range of sources plus substantial amounts of fat and protein. Although these other major nutrients will not contribute directly to the glycaemic response, they are able to modulate it (Collier et al. 1984; Spiller et al. 1987). Despite the substantial scope for interactions between diet constituents, which may influence the glycaemic response, data from mixed meals have been shown to correlate well with predictions based on the individual foods (Wolever \& Jenkins, 1986; Chew et al. 1988; Wolever, 1989). This indicates that a consideration of the glycaemic responses of meal components may be useful when formulating diabetic diets.

\section{CONCLUSIONS}

The present paper has reviewed current dietary recommendations for diabetes and outlined ways in which a wide range of interacting dietary factors may influence post-prandial blood glucose levels. The recommended diabetic diet will assist in regulating plasma glucose excursions and may contribute to alleviating obesity. However, diet-induced variations in post-prandial plasma glucose response may be accompanied by significant changes in the concentrations of insulin in the circulation (e.g. Traianedes \& O'Dea, 1986; Heaton et al. 1988; Behall et al. 1989). Diet components can also significantly influence concentrations of other hormones, including glucagon and gastric inhibitory polypeptide (e.g. Crapo et al. 1981; Collier et al. 1984; Morgan et al. 1990). Variations in the levels of these hormones may be of fundamental importance in diabetic control and they may be implicated in the favourable long-term effects found in diabetic subjects given diets with low glycaemic responses (Brand et al. 1989).

\section{REFERENCES}

Behall, K. M.. Scholfield, D. J., Yuhaniak, I. \& Canary, J. (1989). Diets containing high amylose vs amylopectin starch: effects on metabolic variables in human subjects. American Journal of Clinical Nutrition 49, 337-344.

Bingham, S. A., Pett, S. \& Day, K. C. (1990). Non-starch polysaccharide intake of a representative sample of British adults. Journal of Human Nutrition and Dietetics 3, 333-337.

Birk, Y. \& Peri, I. (1980). Saponins. In Toxic Constituents of Plant Foodstuffs, pp. 161-182 [I. E. Liener. editor]. New York: Academic Press.

Blackburn, N. A. \& Johnson. I. T. (1981). The effect of guar gum on the viscosity of the gastrointestinal contents and on the glucose uptake from the perfused jejunum in the rat. British Journal of Nutrition 46. $239-246$. 
Bornet, F. R. J., Bizais, Y., des Varannes, S. B., Pouliquen, B., Laval, J. D. \& Galmiche, J. P. (1990). $\alpha$-Amylase (EC 3.2.1.1) susceptibility rather than starch viscosity or gastric emptying rate controls plasma responses to starch in healthy humans. British Journal of Nutrition 63, 207-220.

Brand, J. C.. Colagiuri, S., Crossman, S., Allen, A. \& Truswell, A. S. (1989). Low glycaemic index carbohydrate foods improve glucose control in non-insulin dependent diabetes mellitus (NIDDM). Proceedings of the 14th International Congress on Nutrition, Seoul, p. 140.

Brand, J. C. Nicholson, P. L., Thorburn, A. W. \& Truswell, A. S. (1985). Food processing and the glycemic index. American Journal of Clinical Nutrition 43, 1192-1196.

British Diabetic Association, (1991). Dietary recommendations for people with diabetes: an update for the 1990's Journal of Human Nutrition and Dietetics/Diabefic Medicine (In the Press).

Buonocore, V. \& Silano, V. (1986). Biochemical, nutritional and toxicological aspects of alpha-amylase inhibitors from plant foods. In Nutritional and Toxicological Significance of Enzyme Inhibitors in Food, pp. 483-507 [M. Friedman, editor]. New York: Plenum Press

Chew, I., Brand, J. C., Thorburn, A. W. \& Truswell, A. S. (1988). Application of glycemic index to mixed meals. American Journal of Clinical Nutrition 47, 53-56.

Collier, G., McLean, A. \& O'Dea, K. (1984). Effect of co-ingestion of fat on the metabolic responses to slowly and rapidly absorbed carbohydrates. Diabetiologia 26, 50-54.

Collings, P., Williams. C. \& McDonald, I. (1981). Effects of conking on serum glucose and insulin responses to starch. British Medical Journal 282, 1032.

Crapo, P. A., Insel, J., Sperling, M. \& Kolterman, A. G. (1981). Comparison of serum glucose, insulin and glucagon responses to different types of complex carbohydrate in noninsulin-dependent diabetic patients. American Journal of Clinical Nutrition 34, 184-190.

Department of Health (1991). Dietary Reference Values for Food Energy and Nutrients for the United Kingdom. Report on Health and Social Subjects no. 41. London: H.M. Stationery Office.

Englyst, H. \& MacFarlane, G. T. (1986). Breakdown of resistant and readily digestible starch by human gut bacteria. Journal of the Science of Food and Agriculture 37, 699-706.

Federation of American Societies for Experimental Biology (1987). In Physiological and Health Consequences of Dietary Fiber. [S. M. Pilch, editor]. Bethesda, Maryland: Life Sciences Research Office.

Fish, B. C. \& Thompson. L. U. (1991). Lectin-tannin interactions and their influence on pancreatic amylase activity and starch digestibility. Journal of Agricultural and Food Chemistry 39, 727-731.

Friday, K. E.. Childs, M. T., Tsunehara, C. H., Fujimoto, W. Y., Bierman, E. L. \& Ensinck, J. W. (1989). Elevated plasma glucose and lowered triglyceride levels from omega-3 fatty acid supplementation in type II diabetes. Diabetes Care 12, 276-281.

Gans, R. O. B., Heine, R. J. Donker, A. J. M. \& van der Vecn, E. A. (1987). Influence of salt on glycaemic response to carbohydrate loading. British Medical Journal 294, 1252-1253.

Glauber, H., Wallace, P., Griver, K. \& Brechtel, G. (1988). Adverse effects of omega-3 fatty acids in non-insulin-dependent diabetes mellitus. Annals of Internal Medicine 108, 663-668.

Goddard, M. S., Young, G. \& Marcus, R. (1984). The effect of amylose content on insulin and glucose responses to ingested rice. American Journal of Clinical Nutrition 39, 388-392.

Griffiths, D. W. (1979). The inhibition of digestive enzymes by extracts of field bean (Vicia faba). Journal of the Science of Food and Agriculture 30, 458-462.

Haber, G. B., Heaton, K. W., Murphy, D. \& Burroughs, L. F. (1977). Depletion and disruption of dietary fibre, effects on saticty, plasma glucose, and serum insulin. Lancet ii, 679-682

Heaton, K. W., Marcus, S. N., Emmett, P. M. \& Bolton, C. H. (1988). Particle size of wheat, maize, and oat test meals: effects on plasma glucose and insulin responses and on the rate of starch digestion in vitro. American Journal of Clinical Nutrition 47, 675-682.

Horwitz, D. L. (1990). Dietary adjuncts: efficacy and inadequacy. In New Anti-diabetic Drugs, pp. 53-63 [C. J. Bailey and P. R. Flatt, editors]. London: Smith Gordon \& Co Ltd.

Jaffé, W. (1980). Hemagglutinins (Lectins). In Toxic Constituents of Plant Foodstuffs, pp. 73-102 [I. E. Leiner. editor]. New York: Academic Press.

Jenkins, D. J. A., Thorne, M. J., Wolever, T. M. S., Jenkins, A. L., Rao, A. V. \& Thompson, L. U. (1987). The effect of starch-protein interaction in wheat on the glycemic response and rate of in vitro digestion. American Journal of Clinical Nutrition 45, 946-951.

Jenkins, D. J. A., Wesson, V., Wolever, T. M. S., Jenkins, A. L., Kalmusky, J., Guidici, S., Csima, A., Josse, R. G. \& Wong, G. S. (1988). Wholemeal versus wholegrain breads: proportion of whole or cracked grains and the glycaemic response. British Medical Journal 297, 958-960. 
Jenkins, D. J. A., Wolever, T. M. S., Taylor, R. H., Barker, H., Ficlden, H., Baldwin, J. M., Bowling, A. C., Newman, H. C., Jenkins, A. L. \& Goff, D. V. (1981). Glycemic index of foods: a physiological basis for carbohydrate exchange. American Journal of Clinical Nutrition 34, 362-366.

Leeds, A. R. (1982). Modification of intestinal absorption by dietary fiber and fibre components. In Dietary Fibre in Health and Disease, pp. 53-71 [G. V. Vahouny and D. Kritchevsky, editors]. New York: Plenum Press.

Low, A. G. (1990). Nutritional regulation of gastric secretion, digestion and emptying. Nutrition Research Reviews 3, 229-252.

McCance, R. A., Prior, K. M. \& Widdowson, E. M. (1953). A radiological study on the rate of passage of brown and white bread through the digestive tract of man. British Journal of Nutrition 7, 98-104.

Meyer, J. H., Ohashi, H., Dehn, D. \& Thomson, J. B. (1981). Size of liver particle emptied from the human stomach. Gastroenterology 80, 1489-1496.

Morgan, I. M., Tredger, J. A., Wright, J. \& Marks, V. (1990). The effect of soluble- and insoluble-fibre supplementation on post-prandial glucose tolerance, insulin and gastric inhibitory polypeptide secretion in healthy subjects. British Journal of Nutrition 64, 103-110.

Mourot, J., Thouvenot, P.. Couct, C., Antoine, J. M., Krobicka, A. \& Debry, G. (1988). Relationship between the rate of gastric emptying and glucose and insulin responses to starchy foods in young healthy adults American Journal of Clinical Nutrition 48, 1035-1040

Phillipson, B. E., Rothrock, D. W., Connor, W. E., Harris, W. S. \& Illingworth, D. R. (1985). Reduction of plasma lipids, lipoproteins and apolipoproteins by dietary fish oil in patients with hypertriglyceridemia. New England Journal of Medicine 312, 1210-1216.

Satchithanandam, S., Vargofcak-Apker, M., Calvert, R. J., Leeds, A. R. \& Cassidy, M. M. (1990). Alteration of gastrointestinal mucin by fiber feeding in rats. Journal of Nutrition 120, 1179-1184.

Schneeman, B. O. (1982). Pancreatic and digestive function. In Dietary Fibre in Health and Disease. pp. 73-83 [G. V. Vahouny and D. Kritchevsky, editors]. New York: Plenum Press.

Schneeman, B. O. \& Gallaher, D. (1986). Effects of dietary fiber on digestive enzymes. In CRC Handbook of Dietary Fiber in Human Nutrition, pp. 305-312 [G. A. Spiller, editor]. Boca Raton: CRC Press Inc.

Spiller, G. A., Jensen, C. D., Pattison, T. S., Chuck, C. S., Whittam, J. H. \& Scala, J. (1987). Effect of protein dose on serum glucose and insulin response to sugars. American Journal of Clinical Nutrition 46, $474-480$.

Taylor, R. H. (1990). Alpha-glucosidase inhibitors. In New Anti-diabetic drugs, pp. 53-63 [C. J. Bailey and P. R. Flatt, editors]. London: Smith Gordon \& Co Ltd.

Thompson, L. (1986). Phytic acid: a factor influencing starch digestibility and blood glucose response. In Phytic Acid: Chemistry and Applications, pp. 173-194 [E. Graf, editor]. Minneapolis: Pilatus Press.

Thorburn, A. W., Brand. J. C. \& Truswell, A. S. (1986). Salt and the glycacmic response. British Medical Journal 292, 1697-1699.

Torsdottir, I., Alpsten, M., Andersson, D., Brummer, R. J. M. \& Andersson, H. (1984). Effect of different starchy foods in composite meals on gastric emptying rate and glucose metabolism. 1. Comparisons between potatoes, rice and white beans. Human Nutrition: Clinical Nutrition 38C, 329-338.

Trajanedes, K. \& O'Dea, K. (1986). Commercial canning increases the digestibility of beans in vitro and the postprandial metabolic responses to them in vivo. American Journal of Clinical Nutrition 44, 390-397.

Vahouny. G. V. \& Cassidy, M. M. (1985). Dietary fibers and the absorption of nutrients. Proceedings of the Society for Experimental Biology and Medicine 180, 432-446.

Wolever, T. M. S. (1989). The impact of the glycaemic index in the modern diabetic diet. Proceedings of the 14th International Congress on Nutrition, Seoul, pp. 136-138.

Wolever, T. M. S. (1990). Relationship between dietary fiber content and composition in foods and the glycemic index. American Journal of Clinical Nutrition 51, 72-75.

Wolever, T. M. S. \& Jenkins, D. J. A. (1986). The use of the glycemic index in predicting the blood glucose response to mixed meals. American Journal of Clinical Nutrition 43, 167-172.

Würsch, P., Del Vedovo, S. \& Koellreutter, B. (1986). Cell structure and starch nature may be the determinants of the digestion rate of starch in legume. American Journal of Clinical Nutrition 43, 25-29. 